\title{
Coping, Personality and Post Traumatic Stress Disorder in Nurses Affected by Super Storm Sandy
}

\author{
Mary Ellen Roberts, Judith T. Caruso, Eileen H. Toughill, Bonnie A. Sturm \\ Seton Hall University College of Nursing, South Orange, NJ, USA \\ Email: maryellen.roberts@shu.edu
}

How to cite this paper: Roberts, M.E., Caruso, J.T., Toughill, E.H. and Sturm, B.A. (2016) Coping, Personality and Post Traumatic Stress Disorder in Nurses Affected by Super Storm Sandy. Open Journal of Nursing, 6, 643-657.

http://dx.doi.org/10.4236/ojn.2016.69068

Received: August 1, 2016

Accepted: August 29, 2016

Published: September 1, 2016

Copyright $\odot 2016$ by authors and Scientific Research Publishing Inc. This work is licensed under the Creative Commons Attribution International License (CC BY 4.0).

http://creativecommons.org/licenses/by/4.0/ (c) (i) Open Access

\begin{abstract}
Objectives: To identify the incidence of post-traumatic stress disorder experienced by nurses as a result of a natural disaster, and its relationship to personality and coping style. Design and Sample: A descriptive correlational design was used to examine the relationships between and among the variables using an anonymous online survey. Measures: Post Traumatic Stress Disorder (PTSD) was measured using the PTSD-8 [1]. The Brief COPE [2] was used to measure coping style. Personality was measured utilizing the State Trait Personality Inventory [3]. Participants answered demographic questions such as gender and age, and how they were affected by the storm. Results: Over $19 \%$ percent of the nurse participants met the criteria for PTSD. The significant predictors of PTSD were the personality characteristics of state-anxiety, state-trait and trait depression, and the coping strategies of active coping, denial, acceptance, instrumental support, behavioral disengagement, venting and planning. The final regression model explained $90.7 \%$ of the variance in high PTSD-8 score. Conclusions: The findings of this study support the literature and the researchers' belief, that there is a relationship among coping, personality, and PTSD. More research is needed to understand the individual coping mechanisms that nurses utilize during times of stress and how they are related to personality and PTSD.
\end{abstract}

Keywords

PTSD, Coping, Personality, Nurse, Natural Disaster

\section{Introduction}

Usually picturing themselves as caregivers, many nurses became care-recipients during Sandy putting them at risk for PTSD. The authors of this study evidenced colleagues expressing stress, depression and an inability to function when they returned 
to work.

\subsection{Background}

On October 29, 2012 Super Storm Sandy made landfall in New Jersey (NJ) and New York (NY). Sandy struck with a storm surge never before seen in the area, the coasts taking the brunt of the assault. It resulted in the most property damage in the area ever caused by a natural disaster. According to the Federal Emergency Management Agency [4], there were 4.8 million power outages, widespread damage to the transportation infrastructure, and broad communication disruption. Over 650,000 homes received major damage or were destroyed. Over 14 million cubic yards of debris were deposited on roads and waterways impeding travel. Damage at refineries, terminals, and pipelines caused massive gasoline shortages [4]. Those affected experienced significant stressful events, including exposure to extreme weather conditions, displacement from their homes, and lack of basic resources.

The literature supports that victims of natural disasters experience Post-Traumatic Stress Disorder (PTSD) and that there is a relationship between PTSD and coping, and PTSD and personality [5]-[8]. Mason et al. [6] investigated the psychological impact of a flood in the United Kingdom. Criteria for PTSD were met by $27.9 \%$ of this adult sample, $24.5 \%$ for anxiety and $35.1 \%$ for depression. Females had higher mean scores for these variables than men. Having to evacuate, previous experience with flooding and poor health were associated with greater stress. Rational, detached, and avoidant coping strategies were most frequently used, emotional coping the least. In studies following Hurricane Katrina, Kamo et al. (2011) [5] found that women coped better than men, and Oni et al. (2012) [8] found a significant relationship between PTSD and coping strategies in a sample of pregnant women. In a study of New Zealanders after the Canterbury earthquakes of 2010 and 2011 [7], a positive relationship was found between PTSD and neuroticism (a personality trait characterized by anxiety, fear, worry, frustration and loneliness).

The DSM-V diagnostic criteria for PTSD stipulate that the exposure must be an inciting event that involves actual/expected death or serious injury. Symptoms include reexperiencing the traumatic event (intrusive recollection), avoiding stimuli associated with the event (avoidance/numbing), and hyper-arousal (persistent symptoms of increasing arousal) [9]. Countless symptoms, from a persistent and distorted sense of blame of self, to a diminished interest in activities, to an inability to remember key aspects of the event, may occur.

Over seven million American adults age 18 and older, 3.5\% of people in this age group, have PTSD in a given year [10]. Associated factors include psychiatric co-morbidities and poor social-support. Mills et al. (2011) [11] found that $38 \%$ of Katrina survivors experienced PTSD one year after the storm. PTSD was related to have been present during the storm, material losses, losing a loved one and needing healthcare during/after the storm. Females were found to be at higher risk of developing PTSD symptoms. 


\subsection{Statement of the Study Aims, Research Questions, and/or Hypotheses}

The purpose of this pilot study was to examine the incidence of post-traumatic stress disorder (PTSD) in a sample of nurses who self-reported experiencing Super Storm Sandy, and to examine the relationships between and among PTSD, personality and coping (see Figure 1).

\subsection{Research Question}

What are the relationships between and among PTSD, coping, and personality in nurse survivors of Super Storm Sandy?

\section{Design and Sample}

A pilot study was conducted using a cross-sectional, descriptive correlational design to examine the relationships between and among the variables of PTSD, coping, personality and selected demographics one year post Super Storm Sandy. The study took place over a 6 week period. Prior to the study, IRB approval was received. A convenience sample of registered nurse members of NJ or NY state nursing associations who live or work in areas affected by the storm were emailed a solicitation letter explaining the

\begin{tabular}{|c|c|}
\hline \multicolumn{2}{|l|}{ Sidebar Definitions } \\
\hline Post-traumatic stress disorder (PTSD) & A mental health condition, triggered by a terrifying event. \\
\hline Personality Trait & $\begin{array}{l}\text { A stable and characteristic aspect of personality with discrete manifestations } \\
\text { such as attitudes, feelings, and actions. }\end{array}$ \\
\hline Personality State & $\begin{array}{l}\text { A temporary behavior or feeling depending on the situation and motives at a } \\
\text { particular time. }\end{array}$ \\
\hline Coping Strategies & Thoughts or actions that people engage in when under stress. \\
\hline Problem-focused coping & Seeks to solve the stressful event and targets the cause/s of the stress \\
\hline Emotion-focused coping & $\begin{array}{l}\text { Seeks to reduce the negative emotional responses associated with the stress but } \\
\text { not the stressor itself }\end{array}$ \\
\hline Constructive/adaptive & Reduces stress levels \\
\hline Destructive/maladaptive & Stress levels increase \\
\hline COPE Acceptance & Accepting that a difficult situation is real and must be addressed \\
\hline COPE Active Coping & Accepting the stressor, then attempting to decrease its negative outcome/s \\
\hline COPE Behavioral Disengagement & $\begin{array}{l}\text { Stopping the effort of coping and trying to avoid the stressful situation rather } \\
\text { than dealing with it }\end{array}$ \\
\hline COPE Denial & Refusing to acknowledge that an event has occurred \\
\hline COPE Emotional Support & Getting moral support, sympathy, or understanding \\
\hline COPE Humor & Joking about the situation \\
\hline COPE Instrumental Support & Receiving material goods and services or financial aid \\
\hline COPE Planning & Thinking about how to confront the problem), \\
\hline COPE Positive Reframing & Trying to see things in a better light \\
\hline COPE Religion & Turning to religion \\
\hline COPE Self Blame & Seeing oneself as responsible for the problem \\
\hline COPE Self Distraction & Doing something to take your attention off the strong emotion \\
\hline COPE Substance Use & Using drugs or alcohol to take one's mind off the problem \\
\hline COPE Venting & The outward expression of emotions \\
\hline
\end{tabular}

Figure 1. Sidebar definitions. 
intent, voluntary nature and ability to withdraw from the study at any point without consequences. Participants then clicked to the anonymous, on-line survey.

\section{Measures}

PTSD was measured using the PTSD-8 [1], which measures the likelihood of having PTSD. Hansen et al. (2010) [1] developed this short screening instrument for easier clinical use detecting adverse psychological responses. The PTSD-8, an 8-item scale adapted from the first 16 questions of the Harvard Trauma Questionnaire, corresponds to the DSM-IV PTSD criteria. The PTSD-8 measures the following:

1) Recurrent thoughts or memories of the event.

2) Feelings as though the event is happening again.

3) Recurrent nightmares about the event.

4) Sudden emotional or physical reactions when reminded of the event.

5) Avoiding activities that remind you of the event.

6) Avoiding thoughts or feelings associated with the event.

7) Feeling jumpy, easily startled.

8) Feeling on guard correlation.

It had good psychometric properties in three independent studies: 1710 whiplash patients $(a=0.83), 305$ rape victims $(a=0.84)$, and 516 disaster victims $(a=0.85)$ [1]. Items are answered on a four-point Likert scale: 1) "not at all”, 2) "a little", 3) "quite a bit", and 4) "all the time" and measures the three core symptom clusters of the PTSD diagnosis: intrusion, avoidance, hypervigilance. The summed score provides a score for symptom severity, with the threshold of at least one symptom from each PTSD symptom cluster equal to or greater than three. Cronbach's alpha for the current study was 0.899 .

Coping was measured with the 28-item Brief COPE [2]. The tool was derived from the Cope Inventory [12]. In a study of 168 victims of Hurricane Andrew, subscale coefficient alphas ranged from 0.50 to 0.90 with nine greater than 0.65 [2]. The Brief COPE consists of 14 scales with two items each on a 4-point Likert scale, with answers ranging from 1) "I haven't been doing this at all" to 4) "I've been doing this a lot". The 14 scales are measured independently. Higher scores indicate greater intensity of use of that coping strategy. In the current study, 12 of the items showed reliability above the acceptable range of 0.60 . Cronbach's alpha for denial was 0.57 , for behavioral-disengagement 0.53 .

Personality was measured utilizing the State Trait Personality Inventory an 80-item self-report questionnaire measuring state and trait anxiety, anger, depression and curiosity [3]. Cronbach's alphas for the trait and state domains respectively were reported as: Anxiety 0.86 and 0.93, Anger 0.93 and 0.87 , Depression 0.81 and 0.81 , and Curiosity 0.76 and 0.86 . The Inventory has appeared in over 3000 studies and been translated into over 30 languages [13]. Participants answer 40 state items on a 4-point Likert scale describing their present feelings with answers ranging from 1) "Not at all" to 4) "Very much so", and 40 trait items on a 4-point Likert scale where participants describe how 
they generally feel with answers from 1) "Almost Never" to 4) "Almost Always". State and Trait personality domains are scored individually. Higher scores indicate greater disposition in that trait or state. For the current study, Cronbach's alphas were all above 0.70 .

Subjects answered demographic questions describing how they were affected by the storm including whether they were evacuated and the amount of property damage they experienced.

\section{Analytic Strategy}

Analysis was conducted in SPSS V22. The threshold of at least one symptom from each PTSD subscale (intrusion, avoidance, hypervigilance) which was equal to or greater than three was utilized to determine the score on the PTSD-8. Participants were divided into two groups: high-likelihood of PTSD (satisfying the criteria for PTSD-8 score) and low-likelihood (not satisfying the criteria for PTSD-8 score). The Pearson Correlation and Spearman Rho were utilized to determine if there was a correlation between PTSD-8 scores with demographics. Levene's Test for Equality of Variances and Independent $t$-test was utilized to determine the relationship between PTSD scores and the severity of the disaster. Fischer's Exact was utilized to determine the relationship between PTSD scores and flood insurance. Pearson Correlation and a backward stepwise logistic regression were utilized to determine the likelihood of PTSD given coping style and personality.

\section{Results}

The sample was composed of 129 nurse respondents from the NY-NJ area affected by the storm. The majority were female $(\mathrm{n}=123)$ aged 20 - 79, married $(54 \%)$, and employed full time in nursing $(\mathrm{n}=113)$. Almost $60 \%$ were employed in an acute care facility. Forty-five experienced evacuation, from one to 365 days.

Of the 129 respondents, 25 (19.5\%) satisfied the criteria for PTSD. There was no significant correlation between PTSD score and age (rho $(129)=-0.037, p=0.674$ ) nor years practicing nursing $(\mathrm{r}(129)=-0.026, p=0.767)$. Because distribution for marital status was skewed (54\% married, $22.5 \%$ single, and $23.2 \%$ other), it was divided into two groups: married and not married. There was no significant difference between the two marital groups $(\mathrm{F}(1,127)=0.006, p=0.941)$ with PTSD.

The severity of the experience of Sandy was measured by two questions: "How long were you evacuated?" and "Did you have flood insurance?" Forty-five nurses were evacuated. The average length of evacuation was 52.87 days, the median 8 days. For the 45 evacuees, there was no significant correlation between length of evacuation and PTSD. The majority of respondents did not have flood insurance (58\%). There was no significant difference in PTSD score between nurses having flood insurance $(\mathrm{n}=14)$ and those without $(\mathrm{n}=11)$.

There was a wide range of property damage, from none $(\mathrm{n}=42)$ to totally destroyed $(n=9)$. Logistic regression indicated that as damage increased in intensity, the likelih- 
ood of symptoms on the PTSD-8 scale would be 1.8 times more likely to occur. However, the intensity of damage was not significantly correlated to the PTSD-8 score and was not a significant predictor of PTSD.

The most frequently used coping strategies by the entire sample $(\mathrm{N}=129)$ were acceptance $(\mathrm{n}=102)$, active-coping $(\mathrm{n}=89)$, positive-reframing $(\mathrm{n}=87)$, planning $(\mathrm{n}=$ 86), emotional-support $(n=85)$, self-distraction $(n=84)$ and venting $(n=80)$. For those who satisfied the criteria for PTSD $(\mathrm{n}=25)$, acceptance, active-coping and planning were used by $96 \%$, and self-distraction and emotional-support by $92 \%$. See Table 1 for the descriptive statistics for the entire sample and those who did/did not meet the criteria for PTSD. The coping strategies of acceptance and humor were not significantly different between those who scored high on the PTSD-8 and those who did not.

For the entire sample $(\mathrm{N}=129)$ there were high and moderate correlations for many of the coping strategies and personality traits and states. For those with a high PTSD-8 score $(n=25)$, there were strong positive correlations between both behavioral-disengagement and self-blame with state and trait anxiety and depression. The coping strategy of denial was positively and significantly correlated with state depression (see Table 2).

Table 3 shows the correlations between coping strategies and personality with the PTSD-8. There was a significant positive correlation between PTSD and two coping styles. Correlation is significant at the 0.01 and 0.05 level (2-tailed) Behavioral-disengagement was used by $60 \%(n=15)$ of the nurses with a high PTSD- 8 score and selfblame by $68 \%(n=17)$. There were strong positive correlations between both trait and state anxiety and depression with PTSD.

A backward stepwise regression was run to explore a possible model using both coping strategies and personality to explain PTSD $(n=25)$ (see Table 4). The regression

Table 1. Descriptive statistics of the frequency of use of coping strategies.

\begin{tabular}{|c|c|c|c|c|c|c|c|c|c|}
\hline & \multicolumn{3}{|c|}{ Total $(\mathrm{n}=129)$} & \multicolumn{3}{|c|}{ PTSD-8 Not Present $(\mathrm{n}=104)$} & \multicolumn{3}{|c|}{ PTSD-8 Present $(\mathrm{n}=25)$} \\
\hline & Mean & Std. Dev. & Median & Mean & Std. Dev. & Median & Mean & Std. Dev. & Median \\
\hline COPE Acceptance & 5.33 & 2.16 & 6 & 5.18 & 2.27 & 6 & 5.92 & 1.53 & 6 \\
\hline COPE Active Coping & 4.41 & 2.15 & 4 & 4.17 & 2.2 & 4 & 5.40 & 1.63 & 5 \\
\hline COPE Planning & 4.36 & 2.12 & 4 & 4.07 & 2.13 & 4 & 5.60 & 1.63 & 6 \\
\hline COPE Positive Reframing & 4.22 & 2.02 & 4 & 4.05 & 1.99 & 4 & 4.92 & 2.02 & 5 \\
\hline COPE Religion & 4.18 & 2.29 & 4 & 3.89 & 2.24 & 3 & 5.36 & 2.16 & 6 \\
\hline COPE Emotional Support & 4.02 & 1.91 & 4 & 3.75 & 1.88 & 3 & 5.16 & 1.57 & 5 \\
\hline COPE Self Distraction & 3.90 & 1.83 & 4 & 3.66 & 1.8 & 3 & 4.88 & 1.62 & 5 \\
\hline COPE Instrumental Support & 3.88 & 1.91 & 4 & 3.60 & 1.81 & 3 & 5.08 & 1.91 & 6 \\
\hline COPE Venting & 3.58 & 1.57 & 3 & 3.35 & 1.47 & 3 & 4.56 & 1.66 & 4 \\
\hline COPE Humor & 3.16 & 1.61 & 2 & 3.11 & 1.61 & 2 & 3.40 & 1.63 & 3 \\
\hline COPE Self Blame & 2.95 & 1.54 & 2 & 2.71 & 1.3 & 2 & 3.96 & 2.01 & 3 \\
\hline COPE Behavioral Disengagement & 2.50 & 0.90 & 2 & 2.34 & 0.75 & 2 & 3.16 & 1.18 & 3 \\
\hline COPE Substance Use & 2.47 & 1.23 & 2 & 2.29 & 1 & 2 & 3.24 & 1.74 & 2 \\
\hline COPE Denial & 2.36 & 0.81 & 2 & 2.17 & 0.43 & 2 & 3.16 & 1.37 & 3 \\
\hline
\end{tabular}


Table 2. Correlations of coping strategies with personality traits and states.

\begin{tabular}{|c|c|c|c|c|c|c|c|c|}
\hline COPE Strategy & $\begin{array}{c}\text { State } \\
\text { Anxiety }\end{array}$ & $\begin{array}{c}\text { Trait } \\
\text { Anxiety }\end{array}$ & $\begin{array}{c}\text { State } \\
\text { Curiosity }\end{array}$ & $\begin{array}{c}\text { Trait } \\
\text { Curiosity }\end{array}$ & State Anger & Trait Anger & $\begin{array}{c}\text { State } \\
\text { Depression }\end{array}$ & $\begin{array}{c}\text { Trait } \\
\text { Depression }\end{array}$ \\
\hline \multicolumn{9}{|c|}{ All Respondents $\mathrm{N}=129$} \\
\hline Self-Distraction & $0.515^{* *}$ & $0.346^{* *}$ & 0.03 & -0.036 & $0.411^{* *}$ & $0.336^{* *}$ & $0.382^{* *}$ & $0.343^{* *}$ \\
\hline Active Coping & $0.387^{* *}$ & $0.268^{* *}$ & 0.002 & -0.131 & $0.267^{* *}$ & $0.255^{* *}$ & $0.256^{* *}$ & $0.268^{* *}$ \\
\hline Denial & $0.365^{* *}$ & $0.395^{* *}$ & $-0.236^{* *}$ & $-0.302^{* *}$ & $0.287^{* *}$ & $0.182^{*}$ & $0.461^{* *}$ & $0.383^{* *}$ \\
\hline Substance-Use & $0.376^{* *}$ & $0.379^{* *}$ & $-0.207^{*}$ & $-0.189^{*}$ & $0.244^{* *}$ & $0.285^{* *}$ & $0.355^{* *}$ & $0.425^{* *}$ \\
\hline Emotional-Support & $0.355^{* *}$ & $0.223^{*}$ & 0.168 & -0.026 & $0.256^{* *}$ & 0.137 & $0.205^{*}$ & $0.224^{*}$ \\
\hline Instrumental-Support & $0.345^{* *}$ & $0.183^{*}$ & 0.087 & -0.012 & $0.265^{* *}$ & 0.169 & $0.219^{*}$ & $0.185^{*}$ \\
\hline Behavioral-Disengagement & $0.559^{* *}$ & $0.553^{* *}$ & $-0.309^{* *}$ & $-0.401^{* *}$ & $0.532^{* *}$ & $0.408^{* *}$ & $0.599^{* *}$ & $0.598^{* *}$ \\
\hline Venting & $0.423^{* *}$ & $0.326^{* *}$ & 0.027 & -0.165 & $0.381^{* *}$ & $0.317^{* *}$ & $0.335^{* *}$ & $0.337^{* *}$ \\
\hline Positive-Reframing & $0.281^{* *}$ & 0.115 & 0.144 & -0.062 & 0.1 & 0.028 & 0.096 & 0.104 \\
\hline Planning & $0.497^{* *}$ & $0.345^{* *}$ & -0.022 & -0.16 & $0.370^{* *}$ & $0.311^{* *}$ & $0.338^{* *}$ & $0.372^{* *}$ \\
\hline Acceptance & $0.264^{* *}$ & $0.210^{*}$ & 0.052 & -0.096 & 0.168 & $0.211^{*}$ & $0.174^{*}$ & $0.238^{* *}$ \\
\hline Religion & $0.309^{* *}$ & 0.11 & 0.132 & -0.071 & $0.219^{*}$ & 0.112 & 0.152 & 0.142 \\
\hline Humor & $0.329^{* *}$ & $0.273^{* *}$ & 0.157 & -0.077 & $0.217^{*}$ & $0.336^{* *}$ & $0.236^{* *}$ & $0.216^{*}$ \\
\hline Self-Blame & $0.626^{* *}$ & $0.600^{* *}$ & -0.169 & $-0.249^{* *}$ & $0.426^{* *}$ & $0.402^{* *}$ & $0.541^{* *}$ & $0.589^{* *}$ \\
\hline \multicolumn{9}{|c|}{ PTSD-8 Present $\mathrm{n}=25$} \\
\hline Behavioral-Disengagement & $0.478^{*}$ & $0.500^{*}$ & -0.39 & $-0.488^{*}$ & 0.26 & 0.07 & $0.515^{* *}$ & $0.463^{*}$ \\
\hline Denial & 0.16 & 0.24 & -0.13 & -0.28 & 0.11 & -0.19 & $0.412^{*}$ & 0.21 \\
\hline Positive-Reframing & -0.15 & -0.11 & 0.23 & 0.02 & -0.18 & -0.398 & -0.10 & -0.27 \\
\hline Self-Blame & $0.567^{* *}$ & $0.499^{*}$ & -0.28 & $-0.439^{*}$ & 0.25 & 0.13 & $0.473^{*}$ & $0.572^{* *}$ \\
\hline Substance-Use & $0.402^{*}$ & $0.549^{* *}$ & -0.39 & $-0.517^{* *}$ & 0.15 & 0.22 & 0.35 & $0.436^{*}$ \\
\hline
\end{tabular}

\footnotetext{
${ }^{* *}$ Correlation is significant at the 0.01 level (2-tailed). ${ }^{*}$ Correlation is significant at the 0.05 level (2-tailed).
}

model was significant $(\mathrm{F}(11,13)=11.561, p<0.001)$

\section{Discussion}

Much has been written about nurses caring for disaster victims and has examined professional responses to exposure to traumatic events as part of their work or volunteerism. To the authors' knowledge, no research has examined the nurse-as-victim of a natural disaster and its relationship among PTSD, coping and personality.

Nurses in the current study were not exempt from the ravages of Super Storm Sandy: 45 indicated that they were evacuated from their homes, eight for 150 days or more. Nine experienced major damage, some lost their homes entirely. Nurses who view themselves as caregivers now became care-recipients. This experience led nurses, like other storm survivors, to undergo psychological stress. For $19 \%(\mathrm{n}=25)$ of the nurses, this experience led to PTSD. This number is higher than the reported prevalence of PTSD for American adults aged 18 and older (3.6\%), or for American women (9.7\%) [10]. This is lower, however, than the reported incidence of PTSD in disaster survivors. 
Table 3. Correlations between PTSD-8 score, coping style, and personality $(n=25)$.

\begin{tabular}{|c|c|c|}
\hline & Pearson Correlation & Sig. (2-tailed) \\
\hline COPE Behavioral-Disengagement & $0.547^{* *}$ & 0.00 \\
\hline COPE Self-Blame & $0.474^{*}$ & 0.02 \\
\hline COPE Substance-Use & 0.21 & 0.30 \\
\hline COPE Religion & 0.2 & 0.35 \\
\hline COPE Denial & 0.07 & 0.74 \\
\hline COPE Humor & 0.03 & 0.89 \\
\hline COPE Instrumental-Support & 0.02 & 0.94 \\
\hline COPE Positive-Reframing & -0.01 & 0.98 \\
\hline COPE Self-Distraction & -0.07 & 0.74 \\
\hline COPE Active Coping & -0.1 & 0.64 \\
\hline COPE Emotional Support & -0.12 & 0.57 \\
\hline COPE Planning & -0.12 & 0.57 \\
\hline COPE Venting & -0.13 & 0.54 \\
\hline COPE Acceptance & -0.28 & 0.17 \\
\hline State Anxiety Score & $0.607^{* *}$ & 0.00 \\
\hline State Curiosity Score & $-0.506^{* *}$ & 0.01 \\
\hline State Depression Score & $0.500^{*}$ & 0.01 \\
\hline State Anger Score & 0.23 & 0.26 \\
\hline Trait Anxiety Score & $0.468^{*}$ & 0.02 \\
\hline Trait Depression Score & $0.438^{*}$ & 0.03 \\
\hline Trait Anger Score & 0.05 & 0.80 \\
\hline Trait Curiosity Score & -0.37 & 0.06 \\
\hline
\end{tabular}

${ }^{* *}$ Correlation is significant at the 0.01 level (2-tailed). ${ }^{*}$ Correlation is significant at the 0.05 level (2-tailed).

Table 4. Regression using coping style and personality to predict PTSD ( $\mathrm{n}=25)$.

\begin{tabular}{|c|c|c|c|c|c|c|c|}
\hline & \multicolumn{2}{|c|}{ Unstandardized Coefficients } & \multirow{2}{*}{$\begin{array}{c}\begin{array}{c}\text { Standardized } \\
\text { Coefficients }\end{array} \\
\text { Beta }\end{array}$} & \multirow{2}{*}{$\mathrm{t}$} & \multirow{2}{*}{ Sig. } & \multicolumn{2}{|c|}{ Collinearity Statistics } \\
\hline & B & Std. Error & & & & Tolerance & VIF \\
\hline (Constant) & 5.265 & 3.316 & & 1.588 & 0.136 & & \\
\hline State Anxiety Score & 0.535 & 0.115 & 0.740 & 4.645 & 0.000 & 0.281 & 3.555 \\
\hline State Anger Score & 0.193 & 0.075 & 0.386 & 2.561 & 0.024 & 0.314 & 3.183 \\
\hline Trait Anger Score & -0.431 & 0.108 & -0.597 & -3.997 & 0.002 & 0.320 & 3.126 \\
\hline Trait Depression Score & 0.341 & 0.102 & 0.561 & 3.349 & 0.005 & 0.254 & 3.934 \\
\hline COPE Active Coping & 2.429 & 0.443 & 1.002 & 5.480 & 0.000 & 0.213 & 4.686 \\
\hline COPE Denial & -1.451 & 0.322 & -0.504 & -4.504 & 0.001 & 0.570 & 1.754 \\
\hline COPE Instrumental Support & 1.197 & 0.323 & 0.578 & 3.699 & 0.003 & 0.292 & 3.425 \\
\hline COPE Behavioral Disengagement & 1.111 & 0.397 & 0.331 & 2.797 & 0.015 & 0.510 & 1.960 \\
\hline COPE Venting & -0.777 & 0.334 & -0.326 & -2.327 & 0.037 & 0.364 & 2.748 \\
\hline COPE Planning & -3.416 & 0.640 & -1.409 & -5.336 & 0.000 & 0.102 & 9.772 \\
\hline COPE Acceptance & 1.015 & 0.339 & 0.391 & 2.989 & 0.010 & 0.417 & 2.398 \\
\hline
\end{tabular}


Mason et al. (2010) [6] found an incidence of 27.9\% for victims of a flood, and Mills et al. (2011) [11] found an incidence of $38 \%$ for victims of Katrina. After Hurricane, Andrew, David et al. (1996) [14] found that 36\% of their sample met the criteria for PTSD.

Surprisingly in the current study, the number of nurses experiencing PTSD was not significantly correlated to their amount of property damage, whether a nurse was evacuated or the amount of time evacuated. These findings are different from those of David et al. (1996) [14] who found that material losses was related to PTSD, and Mason et al. (2010) [6] and Mills et al. (2011) [11] who found that both material losses and evacuation were related to PTSD. This pilot study used a convenience sample with a wide range of evacuation time, from one day to a year and the lack of statistical significance may be due to the small number of nurses who experienced a major loss $(n=9)$ or evacuation for a long period of time $(n=8)$.

Declercq, Meganck, Deheegher, and Van Hoorde (2011) [15] studied 136 nurses and ambulance personnel (28\% nurses) working in military facilities. They found that how health care workers responded to a stressor contributed to the development of PTSD symptoms. Fear, helplessness and horror were associated with developing symptoms. The authors of the current study considered that coping strategies would be related to personality and that strategies would vary based on how participants experienced/ viewed the event. While coping is one of the most widely studied topics, and there is much disagreement as to which coping strategies are helpful in relieving stress. Coping behaviors have been categorized in the literature as emotional or problem-solving, and as constructive/adaptive or destructive/maladaptive.

Carver (1997) [2] viewed planning, active-coping, and instrumental support as problem-focused coping strategies, and positive-reframing, religion, humor, and seeking emotional support as emotion-focused coping. Less useful/maladaptive strategies include behavioral-disengagement, venting, self-distraction, self-blame, and substance use.

All three types of coping strategies were found to explain the current model, however, the results were not as expected. Use of the positive-coping strategies of active-coping and instrumental-support increased the PTSD score by 2.429 and 1.197 respectively, while the positive-coping mechanism of planning decreased it by 3.416 . Emotionfocused coping was unexpected in that acceptance increased the PTSD score by 1.015 while denial was somewhat protective, decreasing the score by 1.451 . Review of the less useful coping strategies of behavior-disengagement and venting indicated a variance in that while venting was somewhat protective in reducing the PTSD score $(-0.777)$, and behavioral disengagement was not (1.111).

Carver et al. (1989) [12] felt that after a major life event individuals might utilize both emotional and problem-focused coping in the short term and that emotion-focused coping might predominate as individuals are overwhelmed with major disruption and envision. Mason et al. (2010) [6] found that emotion-focused coping was the least used form of coping six months after a flood. In the current study, two problem-focused and two emotion-focused were most frequently used, and no one type of 
coping was found to be largely protective of PTSD severity. Planning had the largest effect on explaining the model and decreasing PTSD severity (-3.416).

Folkman \& Lazarus (1980) [16] held that three processes occurred in reaction to a stressor. Primary appraisal involves perceiving a threat. Secondary appraisal means thinking of a possible response to the threat, and coping is executing that response. Carver et al. (1989) [12] considered that planning is a secondary appraisal, whereas active-coping occurs during the coping phase when a plan is actually implemented. While thinking about how they might respond to the events of Super Storm Sandy (planning) reduced the severity of the PTSD score for the sample, while the actual ability to implement that plan by active coping was not, and increased the severity of PTSD symptoms. Nurses are planners and doers so it might be expected that their inability to implement their plans would increase the severity of the symptoms of PTSD. These findings must be viewed with some caution, as the VIF for the coping strategy of planning was 9.772 , and for active coping it was 4.686 , indicating that some collinearity of variables may exist.

More research is needed on the use of instrumental support and its effect on PTSD symptoms. Oni et al. (2012) [8] found that this problem-focused coping mechanism was associated with worsened symptoms of PTSD $(\mathrm{p}<0.05)$ after Katrina. Similar findings were noted in the current study where instrumental support increased the PTSD score by $1.197(\mathrm{p}=0.003)$. Although the majority of respondents with a high score on the PTSD-8 had flood insurance, there was no significant difference in PTSD score between those with and without this instrumental-support. The newspapers continue to be awash with horror stories of Sandy survivors whose insurance did not cover any or the majority of needed home repairs. If support is still required years after the storm, and the expected insurance is not sufficient, it is understandable that this might lead to continued or escalating stress. Instrumental-support had small to moderate positive correlations with three personality states (domains related to the present situation): state depression $(0.219, \mathrm{p}<0.05)$ state anger $(0.265, \mathrm{p}<0.01)$ and state anxiety $(0.345, \mathrm{p}<0.01)$. Thus nurses required to accept their current situation led to increased stress $(B=1.105)$. These viewpoints regarding insurance are based on conversations with nurses and are not fully explored within this study. Improved understanding of how nurses view this coping strategy is warranted.

The emotion-focused coping strategy of positive-reframing was the $3^{\text {rd }}$ highest coping strategy used by the entire sample, used by $67 \%$ of all participants. And while $80 \%$ $(\mathrm{n}=20)$ of those with high PTSD-8 scores used this strategy, it was not found to explain the final model. Different results were found by Borja and Callahan (2008) [17] in their study of victims of Hurricane Rita. Reframing was one of the predictors of good mental health which accounted for $43 \%$ of the variance, while Oni et al. (2012) [8] found that positive-reframing was not significantly associated with PTSD in the Hurricane Katrina victims they studied. More investigation of this coping strategy is warranted.

The researchers also theorized that personality was related to the type of coping 
strategies that nurses would use, and that adaptive coping strategies would be negatively correlated with personality traits and states of anxiety, anger and depression. Surprisingly, most of coping strategies were positively correlated with these personality domains. More research is clearly needed on this finding. Do nurses, because of their education and experience, utilize all types of coping strategies regardless of personality traits or the situation in which they find themselves in order to be able to function for the good of others?

The literature varies in findings of PTSD found in health care providers working during or after a disaster. Stewart, Mitchell, Wright and Loba (2004) [18] found that $46 \%$ of disaster workers met the criteria for PTSD after the Swiss Air crash. Jonsson, Segesten and Mattsso (2003) [19] and Clohessy and Ehlers (1999) [20] found PTSD rates of $12.2 \%$ and $21 \%$, respectively, in ambulance drivers exposed to repeated traumatic events. While Declercq et al. (2011) [15] found no relationship between the frequency of encountered incidents and PTSD, they did find that supply and resource limitations had the most intense effect. More research is needed to understand how health care workers are impacted by disasters as part of their work life, and when they become the victim rather than the caregiver. In the current study, it is unclear how many of the participants were not only victims but returned to their work life of helping others, and what impact that had on acquiring or being protective of PTSD.

The relationship theorized by the researchers that personality and coping strategies would be related to PTSD was found. The final model $(n=25)$, using coping strategies and personality traits and states, explained $90.7 \%$ of the variance to predict a high PTSD-8 score. Predictors included trait and state anger, trait depression and state anxiety. Studies of PTSD have found anger as the major symptom in predicting PTSD. Novaco and Chemtob (2002) [21] studied 143 Vietnam veterans and found anger as the greatest predictor of PTSD, accounting for over $40 \%$ of the variance. Interestingly, in the current study, only trait anger $(B=-0.431, p=0.002)$ was protective of nurses from PTSD symptoms, while being angry in the current situation (state anger) was not ( $\mathrm{B}=$ $0.192, p=0.02$ ). As nurses experienced anger in reaction to Sandy, their PTSD symptoms were likely to increase or increase in intensity.

Gros et al. (2010) [22] theorized that depression was inherent in the PTSD diagnostic criteria and, therefore, may or may not significantly affect the relationship between PTSD and anger. Spinhoven et al. (2015) [23] studied 359 individuals exposed to a traumatic event, $14.4 \%$ of whom developed post-traumatic PTSD. They found that depression and trait rumination of the event predicted PTSD but explained only $17 \%$ of the variance. For the current study, trait depression (a tendency towards chronic feelings of sadness and a general loss of interest) had a positive relationship with PTSD. Nurses who usually felt sad were more at risk for PTSD symptoms or the severity of the symptoms. Interestingly, this supported the researchers' idea that what we observed in nursing colleagues with trait depression was increased PTSD symptoms and that it was related to personality.

State anxiety had the highest correlation with PTSD of all the personality domains (B 
$=0.535, p=0.000$ ). It is not unexpected that victims of Sandy would have a high level of state anxiety in the current situation, and that it would increase PTSD symptomology. The severity of PTSD symptoms increased as anxiety in the current situation increased. But unlike Weems et al. (2007) [24] who found pre-disaster anxiety in children after Hurricane Katrina predicted post-traumatic stress, trait anxiety did not explain the current model. Mason et al. (2010) [6] found that women had higher scores for PTSD and anxiety than men. The current findings may be related to the small number of male nurses $(n=6)$ who responded to the survey. So although there was a strong relationship between state anxiety and PTSD $(0.607, \mathrm{p}<0.01)$ these findings must be viewed with caution.

\section{Limitations}

This is a pilot study and thus has limited generalizability. The lack of statistical significance in demographic questions, particularly the relationship between property damage, evacuation and PTSD may be due to the small number of subjects who experienced a major loss or evacuation. The sample was predominately female with only six men responding. Eighty-eight percent of respondents were employed in acute care settings so that generalizing these results to all nurses must be done cautiously.

\section{Implications for Additional Research}

Based on the findings of this pilot study, more research on nurses-victims of a disaster and the relationship of PTSD to coping strategies and personality in this population is indicated. The majority of coping strategies that the subjects employed were positively correlated with state and trait personality domains regardless of the strategies being considered adaptive or maladaptive.

More study is indicated regarding coping mechanisms in different populations. The findings that instrumental support, used by $80 \%$ of the 25 nurses who scored high for symptoms of PTSD and increased the severity of PTSD symptoms, deserves further inquiry. Carver et al. (1989) [12] found that instrumental support was problem-focused and helped reduce stress. Does this coping strategy vary in different populations and different situations?

The number of nurses who scored high on the PTSD- 8 was higher than the average found in the general population but lower than that found in other victims of disasters. Was this number related to the response rate or to a characteristic of nurses? Are nurses more resilient because of their education and practice experience? How does work-life and setting impact a nurse's ability to withstand a natural disaster?

This study supports the use of short assessment tools. The PTSD-8 involves little participant burden and makes research immediately after a stressful event more feasible. It allows identification of responders quickly after a stressful situation and affords them the opportunity to for immediate support.

Similarly, the Brief COPE showed good reliability. Additional research with this short tool regarding the individual strategies, as well as the entire tool as a composite 
score, will allow study of this concept with less burden for users.

This study found that personality was correlated with coping and PTSD. It is common practice to look at personality styles of management staff to support them in being more effective in their positions. Development of short personality tools, as was done with the PTSD-8 to assess PTSD, would allow nurses at all levels of practice to understand more about themselves and how they function in everyday life and in stressful situations. In a study of 248 emergency room nurses exposed to traumatic work events, not related to a disaster, Adriaenssens, de Gucht and Maes (2012) [25] found that almost 9\% met the clinical level of PTSD. Knowing more about how and why nurses react to stress will help provide support, intervention and educational programs for nurses at all levels.

It is important to remember that nurses, when faced with difficult personal or professional situations, are at risk for unresolved stress. When faced with massive natural disasters such as Super Storm Sandy, nurses go into high-gear helping others. They need to know to take care of themselves. Disaster preparedness programs prepare nurses for their professional role. Expansion of these, to help nurses understand their risk factors based on personality traits and the coping measures that might be most helpful to reduce stress is indicated. Additional research to better understand how nurses are affected during stressful times will help nursing managers plan for staffing during times of disasters and oversee their staff during these difficult situations. Finally, in depth qualitative inquiry, giving voice to nurses' experiences would help provide additional understanding about what the ravages of this storm meant to participants.

\section{References}

[1] Hansen, M., Andersen, T.E., Armour, C., Elklit, A., Palic, S. and Mackrill, T. (2010) PTSD-8: A Short PTSD Inventory. Clinical Practice \& Epidemiology in Mental Health, 6, 101-108 http://dx.doi.org/10.2174/1745017901006010101

[2] Carver, C. (1997) You Want to Measure Coping but Your Protocol's Too Long: Consider the Brief COPE. International Journal of Behavioral Medicine, 4, 92-100. http://dx.doi.org/10.1207/s15327558ijbm0401_6

[3] Spielberger, C.D., Gorsuch, R.L., Lushene, R., Vagg, P.R. and Jacobs, G.A. (1983) Manual for the State Trait Anxiety Inventory. (Form Y). Consulting Psychologists Press, Palo Alto.

[4] Federal Emergency Management Agency (2013) 6 Months Report: Superstorm Sandy from Pre-Disaster to Recovery (Data File).

http://www.fema.gov/disaster/4086/updates/6-months-report-superstorm-sandy-pre-disast er-recovery

[5] Kamo, Y., Henderson, T. and Roberto, K. (2011) Displaced Older Adults' Reactions to and Coping with the Aftermath of Hurricane Katrina. Journal of Family Issues, 32, 1346-1370. http://dx.doi.org/10.1177/0192513x11412495

[6] Mason, V., Andrews, H. and Upton, D. (2010) The Psychological Impact of Exposure to Floods. Psychology, Health \& Medicine, 15, 61-73.

http://dx.doi.org/10.1080/13548500903483478

[7] Kuijer, R.G., Marshall, E.M. and Bishop, A.N. (2014) Prospective Predictors of Short-Term Adjustment after the Canterbury Earthquakes: Personality and Depression. Psychological 
Trauma: Theory, Research and Practice, 6, 361-369. http://dx.doi.org/10.1037/a0034591

[8] Oni, O., Harville, E.W., Xiong, X. and Buekens, P. (2012) Impact of Coping Styles on Post-Traumatic Stress Disorder and Depressive Symptoms among Pregnant Women Exposed to Hurricane Katrina. American Journal of Disaster Medicine, 7, 199-209.

[9] American Psychiatric Association (2013) Diagnostic and Statistical Manual of Mental Disorders. 5th Edition, American Psychiatric Publishing, Arlington.

[10] Kessler, R.C., Chiu, W.T., Demler, O., Merikangas, K.R. and Walters, E.E. (2005) Prevalence, Severity, and Comorbidity of 12-Month DSM-IV Disorders in the National Comorbidity Survey Replication. Archives of General Psychiatry, 62, 709-709. http://dx.doi.org/10.1001/archpsyc.62.7.709

[11] Mills, L., Mills, T., Macht, M., Levitan, R., De Wulf, A. and Alfonso, N. (2011) Post-Traumatic Stress Disorder in an Emergency Department Population One Year after Hurricane Katrina. The Journal of Emergency Medicine, 43, 76-82. http://dx.doi.org/10.1016/j.jemermed.2011.06.124

[12] Carver, C.S., Scheier, M.F. and Weintraub, J.K. (1989) State-Trait Anxiety Inventory. Journal of Personality and Social Psychology, 56, 267-283. http://dx.doi.org/10.1037/0022-3514.56.2.267

[13] Spielberger, C.D. (1989) State-Trait Anxiety Inventory: Bibliography. 2nd Edition, Consulting Psychologists Press, Palo Alto.

[14] David, D., Mellman, T.A., Mendoza, L.M., Kulick-Bell, R., Ironson, G. and Schneiderman, N. (1996) Psychiatric Morbidity Following Hurricane Andrew. Journal of Traumatic Stress, 9, 607-612. http://dx.doi.org/10.1002/jts.2490090316

[15] Declercq, F., Meganck, R., Deheegher, J., and Van Hoorde, H. (2011) Frequency of and Subjective Response to Critical Incidents in the Prediction of PTSD in Emergency Personnel. Journal of Traumatic Stress, 24, C133-C136. http://dx.doi.org/10.1002/jts.20609

[16] Folkman, S. and Lazarus, R.S. (1980) An Analysis of Coping in a Middle-Aged Community Sample. Journal of Health and Social Behavior, 21, 219-239. http://dx.doi.org/10.2307/2136617

[17] Borja, S.E. and Callahan, J.L. (2008) Recovery Following Hurricane Rita: A Pilot Study of Preexisting and Modifiable Aspects of Positive Change. Traumatology, 14, 12-19. http://dx.doi.org/10.1177/1534765607312688

[18] Stewart, S.H., Mitchell, T.L., Wright, K.D. and Loba, P. (2004) The Relations of PTSD Symptoms to Alcohol Use and Coping Drinking in Volunteers Who Responded to the Swissair Flight 111 Airline Disaster. Journal of Anxiety Disorders, 18, 51-68. http://dx.doi.org/10.1016/j.janxdis.2003.07.006

[19] Jonsson, A., Segestern, K. and Mattsson, B. (2003) Post-Traumatic Stress among Swedish Ambulance Personnel. Journal of Emergency Medicine, 20, 79-84. http://dx.doi.org/10.1136/emj.20.1.79

[20] Clohessy, S. and Ehlers, A. (1999) PTSD Symptoms, Response to Intrusive Memories and Coping in Ambulance Service Workers. The British Journal of Clinical Psychology, 38, 251265. http://dx.doi.org/10.1348/014466599162836

[21] Novaco, R.W. and Chemtob, C.M. (2002) Anger and Combat-Related Posttraumatic Stress Disorder. Journal of Traumatic Stress, 15, 123-132. http://dx.doi.org/10.1023/A:1014855924072

[22] Gros, D., Price, M., Magruder, K.M. and Frueh, B.C. (2012) Symptom Overlap in Posttraumatic Stress Disorder and Major Depression. Psychiatry Research, 196, 267-270. 
[23] Spinhoven, P., Penninx, B.W., Krempeniou, A., van Hermert, A.M. and Elzinga, B. (2015) Trait Rumination Predicts Onset of Post-Traumatic Stress Disorder through Trauma-Related Cognitive Appraisals: A 4-Year Longitudinal Study. Behaviour Research and Therapy, 71, 101-109. http://dx.doi.org/10.1016/j.brat.2015.06.004

[24] Weems, C.F., Pina, A.A., Costa, N.M., Watts, S.E., Taylor, L.K. and Cannon, M.F. (2007) Predisaster Trait Anxiety and Negative Affect Predict Posttraumatic Stress in Youths after Hurricane Katrina. Journal of Consulting and Clinical Psychology, 75, 154-159. http://dx.doi.org/10.1037/0022-006X.75.1.154

[25] Adriaenssens, J., de Gucht, V. and Maes, S. (2012) The Impact of Traumatic Events on Emergency Room Nurses: Findings from a Questionnaire Survey. International Journal of Nursing Studies, 49, 1411-1422. http://dx.doi.org/10.1016/j.ijnurstu.2012.07.003

Submit or recommend next manuscript to SCIRP and we will provide best service for you:

Accepting pre-submission inquiries through Email, Facebook, LinkedIn, Twitter, etc. A wide selection of journals (inclusive of 9 subjects, more than 200 journals)

Providing 24-hour high-quality service

User-friendly online submission system

Fair and swift peer-review system

Efficient typesetting and proofreading procedure

Display of the result of downloads and visits, as well as the number of cited articles

Maximum dissemination of your research work

Submit your manuscript at: http://papersubmission.scirp.org/ 